\title{
Taming the Zebra: Unravelling the barriers to diagnosing aortic dissection
}

\begin{abstract}
Aortic dissection (AD) continues to present a significant diagnostic dilemma to the modern-day Emergency Physician. There are several factors that contribute to delayed or missed diagnosis. These not only relate to the condition but also to the treating clinician and the context in which a diagnosis is made or not made. Failure to consider $A D$ is often implicated in missed or delayed diagnoses, however other types of cognitive bias exist that Emergency Physicians must be aware of. Such awareness must extend to error-producing conditions that exist within the busy Emergency Department (ED) environment.
\end{abstract}

This article provides a thematic analysis of the barriers that may prevent or delay diagnosis of AD with a focus on the condition, the clinician and the context.

Awareness of these barriers will improve diagnostic acumen and ultimately, improve patient outcomes.

\section{The condition}

Aortic dissection boasts an unfortunate lethal triad- it is rare, lethal and can present atypically despite the 'textbook description'. Most are taught to consider $A D$ where chest pain is described as 'severe, unremitting, tearing or ripping in nature and maximal at onset' which 'may be migratory'. acute coronary syndrome and pulmonary embolism, $A D$ is often overlooked in the assessment of acute chest pain. The incidences of both conditions are known to be orders of magnitude higher and therefore more accessible as a possible diagnosis to an assessing clinician. The reported incidence of $\mathbf{A D}$ varies in the available literature but is thought to be 3.5 per 100,000 cases ${ }^{2}$. One study reported an ED incidence of 1 in 12,200 patients per year from a database of 9.5 million ED patients ${ }^{3}$.

Timely diagnosis is crucial. Without treatment, Type A dissection is reported to have a cumulative mortality of $1-2 \%$ per hour, rising to an $80 \%$ mortality within two weeks ${ }^{4}$. Similarly, Type B dissections can also carry up to $70 \%$ mortality if untreated in higher risk groups ${ }^{5}$.

Whilst focus is often on preventing mortality, it is important to recognise the significant morbidity in those who survive AD. When an AD occurs, a tear forms in the intima of the aorta and then propagates between this and the media, with the potential to track proximally, distally or both (Figure 1). Proximally it can lead to cardiac tamponade secondary to haemopericardium or rupture. Conversely, the dissection can continue to descend the aorta causing a wide range of possible

This is the author manuscript accepted for publication and has undergone full peer review but has not been through the copyediting, typesetting, pagination and proofreading process, which may lead to differences between this version and the Version of Record. Please cite this article as doi: 10.1111/1742-6723.12871

This article is protected by copyright. All rights reserved. 
presentations including stroke, paralysis, limb ischaemia or even hoarse voice (Ortner's Syndrome) ${ }^{6}$. The wide assortment of presentations presents a considerable diagnostic dilemma even for experienced Emergency Physicians at the bedside. It has been reported that up to $38 \%$ of ADs are missed in the initial presentation to hospital ${ }^{7}$. Looking for presence or absence of cardinal features of the classic presentation of aortic dissection may not suffice as an appropriate assessment.

The clinician

"When you hear hoof beats, think of horses not zebras"

Dr Theodore Woodward

All clinicians are human and it is well-known that clinical decision making can be prone to cognitive bias and lead to error. Patient safety researchers have sought to classify these errors including those that relate to missed or delayed diagnosis.

Of concern are conditions that are uncommon but potentially life-threatening. These may not be considered at all for (for a variety of reasons) or considered early but dismissed due to its prevalence (known as 'playing the odds') or gestalt opinion ${ }^{8}$. The reluctance to pursue a rare diagnosis is described as the 'Zebra Retreat' ${ }^{8}$. This references the classic idiom attributed to $\mathrm{Dr}$ Theodore Woodward that urged medical students to think of more common conditions first. Ironically, this saying may have inadvertently perpetuated a mindset that biases clinicians aware from the consideration of a rare diagnosis or 'zebra'. Of these zebras, aortic dissection is arguably the deadliest.

There are a group of errors the ED clinicians should be aware of and consider when supervising junior medical staff in regard to AD.

Availability bias:

This pertains to familiarity with one diagnosis over the other such that a clinician may choose to pursues a diagnosis that comes more readily to mind e.g. acute coronary syndrome ${ }^{8}$.

Omission bias:

This pertains to doing something easy and omitting (or avoiding) something difficulty $^{8}$. This may relate to ease of access, cost or convenience. Obtaining serial troponins is easier, cheaper and associated with fewer barriers and risks that obtaining a CT aortogram.

\section{Confirmation bias:}


The clinician seeks evidence to include their favoured diagnosis as opposed to exclude it ${ }^{8}$. An example of this would be where a patient with a known reflux that presents with chest pain that is not typical of their usual reflux symptoms. The Emergency Physician prescribes a combination of antacid and local anaesthetic and sends the patient home after some improvement in pain rather than considering why it might NOT be reflux.

\section{Search satisfying:}

Almost converse to fixation on a specific diagnosis, failure to consider alternative diagnoses can similar lead to error occurring. Search satisfying refers to the tendency to call off a search once something is found and not considering additional diagnoses subsequent to this ${ }^{8}$. For example, chest pain reproducible on palpation leads the clinician to a musculoskeletal cause rather than look further for other differentials.

\section{Sutton's slip:}

Focusing on the most obvious answer is also referred to as Sutton's slip and prevents clinicians for look further ${ }^{8}$. AD may not be considered in a patient who presents with retrosternal chest pain and ST elevation on an ECG until it is subsequently diagnosed in the cardiac catheter laboratory.

\section{Diagnosis momentum:}

This refers to the tendency for a decision to be established despite other evidence $^{8}$. This is a continual challenge for Emergency Physicians, who inherit care of patients from other clinicians e.g. paramedics, junior doctors and even other Emergency Physicians. Patients presenting with AD may be 'handed over' to the ED clinician as 'query ischaemic chest pain' because of assessment combined with cognitive bias and level of experience culminating in commitment to a pathway that is often geared towards exclusion of acute coronary syndrome rather than other causes.

Patients may fail to progress as expected and this should serve as a prompt for clinicians to reconsider the differential diagnoses currently being treated. For example, a patient with ongoing chest pain despite normal cardiac investigations. Unwillingness to give up a diagnosis is known as 'sunk costs' and may lead to a clinician dismissing ongoing symptoms as being due to 'patient factors' and fail to recognise the significance of failure to respond to treatment ${ }^{8}$.

The context 
The ED is a unique medical environment that sees clinicians of varying experience assess, diagnose and manage a wide range of medical problems, which are of varying acuity and severity, across all ages at any time of the day. This environment coupled with the experience of the treating clinician and the individual patients seen can create a setting in which the likelihood of error occurring is higher.

ED clinicians work in busy, high-stress environments, which can lead to errors occurring. Conditions that can lead to errors occurring in patients with aortic dissection are not dissimilar to those for other conditions. Error-producing conditions can be defined as intrinsic or extrinsic ${ }^{9}$.

Intrinsic error-producing conditions include narrow time windows for assessment such as those imposed by National Emergency Access Target. Multi-tasking (multiple patients), fatigue, surge phenomena and multiple transitions of care (e.g. movement from the waiting room to the 'main floor' to Short Stay) are also considered intrinsic error-producing conditions. High volume of presentations can lead to patients being admitted inappropriate to a Short Stay Unit pathway. Of note, whilst rapid chest pain assessment pathways for acute coronary syndrome have improved time to discharge for low-risk chest pain, if inappropriately utilised, these may facilitate the inappropriate discharge of a patient presenting with aortic dissection.

Extrinsic error-producing conditions include overcrowding, inadequate staffing, inadequate supervisory capacity, and exit block. The impact of these conditions is acknowledged in a report from a Coronial Roundtable held by the Victorian State Coroner with representatives from the local Emergency Physician group following several reported deaths, where the diagnosis was missed ${ }^{7}$. Of those recommendations, one pertained to care being taken by ED clinicians supervising junior medical staff to ensure they have considered an appropriate list of differentials, include the rare, lethal and atypical such as AD. Whilst retrospectively, a missed diagnosis of AD may seem 'unmissable', in a busy, overcrowded department when hearing the third resident's presentation for the hour, the obvious is likely to be not obvious.

\section{Conclusion}

Aortic dissection is a rare, atypical and lethal condition where delayed diagnosis can result in significant morbidity and mortality. Dependence on 'classical' clinical features and presentation is unlikely to suffice in making a diagnosis. There are several barriers when considering this diagnosis that relate to the condition, the clinician and the context. 
Greater clinician awareness and education is only one aspect of quality improvement but needs to be coupled with cognizant and sensible clinical practice. These extend beyond the Emergency Physician to any clinician practicing in the Emergency Department. Opportunities to reduce cognitive bias and mitigate errorproducing conditions should be explored to improve patient outcomes in relation to this rare but devastating disease.

Future research is also required to examine the potential use of clinical decision scores (such as the Aortic Dissection Detection Risk Score), investigations such DDimer testing and clinical decision support aids available in real-time.

A recent case at our institution has prompted avid discussion and the formation of the Heidelberg Aortic Dissection Evaluation Study (HADES) group, which aims to contribute an Australian perspective to the global Emergency Medicine Aortic Dissection research experience as well as examining this issue from a clinical perspective.

\section{References:}

1. Cameron, P. (2014). Textbook of adult emergency medicine (4th Edition). Edinburgh: Churchill Livingstone.

2. Clouse WD, Hallett JW Jr, Schaff HV, et al. Acute aortic dissection: populationbased incidence compared with degenerative aortic aneurysm rupture. Mayo Clin Proc. 2004 Feb. 79(2):176-80

3. Alter S, Eskin B, Allegra J. Diagnosis of aortic dissection in emergency department patients is rare. West J Emerg Med. 2015;16:629-31

4. Coady MA, Rizzo JA, Goldstein L, Elefteriades JA. Natural history, pathogenesis, and etiology of thoracic aortic aneurysms and dissections. Cardiol Clin 1999; 17(4): 615-35; vii

5. Hagan PG, Nienaber CA, Isselbacher EM, Bruckman D, Karavite DJ, Russman PL, et al. The International Registry of Acute Aortic Dissection (IRAD): new insights into an old disease. JAMA 2000; 283(7): 897-903

6. Tintinalli JE, Kelen GD, Stapczynski JS, Ma, OJ, Cline DM, editors. Tintinalli's Emergency Medicine. 6th ed. New York: McGraw-Hill; 2004

7. Jelinek GA, Bugeja LC, Spanos PA, Neate SL, Bergman RL, Ranson DF. Collaboration between the Coroner and clinicians: efforts to improve outcomes from aortic dissection. Med J Aust 2014; 201:607-9

8. Campbell SG, Croskerry P, Bond WF. Profiles in patient safety: a "perfect storm" in the emergency department. Acad Emerg Med. 2007, 14: 743-749

9. Croskerry P. ED Cognition: Any decision by anyone at any time. Canadian Journal of Emergency Medicine. 2014, 16:13 


\section{Figure Reference:}

Layers of the aortic wall, digital image of aortic dissection pathophysiology, International Registry of Aortic Dissection, accessed 3 August 2017

http://www.iradonline.org/about.html 


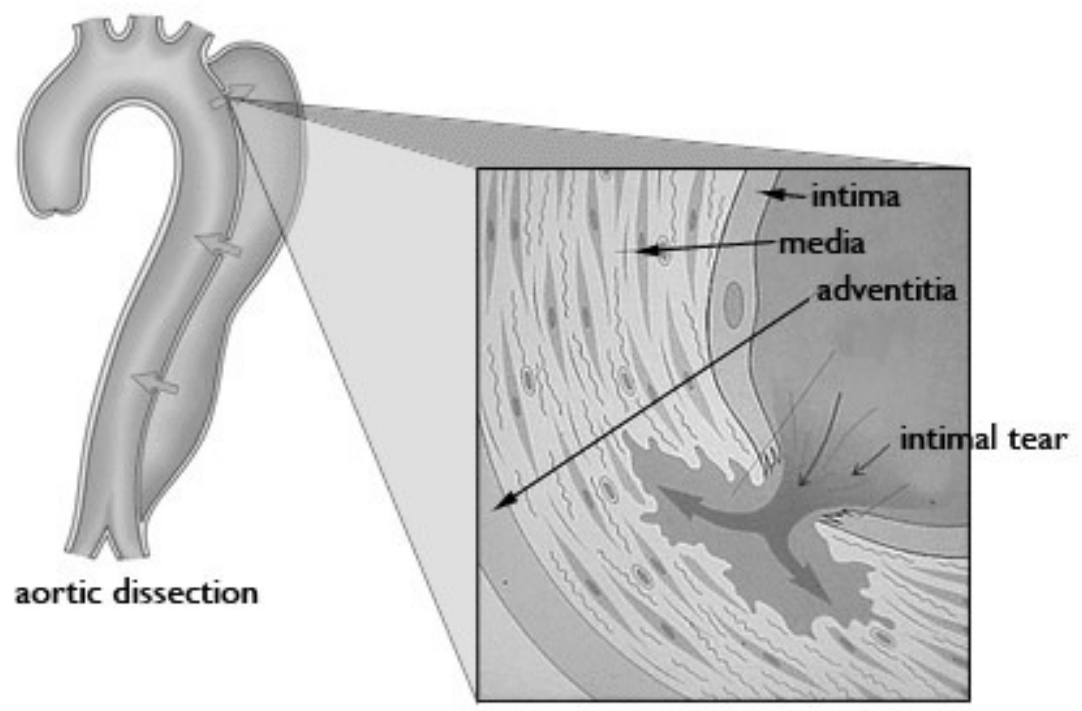

Figure 1.jpg

This article is protected by copyright. All rights reserved. 


\section{University Library}

\section{- M M I E R R A A gateway to Melbourne's research publications}

Minerva Access is the Institutional Repository of The University of Melbourne

Author/s:

Rotella, J-A;Yeoh, M

Title:

Taming the zebra: Unravelling the barriers to diagnosing aortic dissection

Date:

2018-02-01

Citation:

Rotella, J. -A. \& Yeoh, M. (2018). Taming the zebra: Unravelling the barriers to diagnosing aortic dissection. EMERGENCY MEDICINE AUSTRALASIA, 30 (1), pp.119-121. https:// doi.org/10.1111/1742-6723.12871.

Persistent Link:

http://hdl.handle.net/11343/293497 